\title{
AN EXPERIMENTAL STUDY ON OBSERVED HEATING CHARACTERISTICS OF URBAN PAVEMENT
}

\author{
Adebayo-Aminu Sarat And Muhammad Abu Eusuf \\ adesarat@yahoo.com
}

\begin{abstract}
Urban climate is modified resulting in its temperature warmer and drier than surrounding sub urban and rural area. One of the major causes of the modification is built environment which is the process of urbanization where vegetated surfaces are converted to asphalt and concrete surfaces. Temperature distribution in urban canopy layer is highly affected by the urban Iradiation balance. Solar radiation incident on the urban surfaces is absorbed and then transformed to sensible heat. Most of the solar radiation impinges on roofs, and the vertical walls of the buildings, and the ground level. Outdoor experiments were conducted to investigate the effects of different movement of materials on the urban thermal environment. Meteorological conditions such as air temperature, pavement surface temperature, relative humidity and wind velocity were recorded to determine the heating characteristics and temperature differences among asphalt, concrete, interlocking bricks and grass surfaces. Additionally, surface albedo was also measured in order to calculate the rate of reflectivity of the four porous and non- porous pavements. This paper confirms that the net balance between the solar gains and the heat loss by the emitted long wave radiation determines the thermal balance of urban areas. Because the radiant heat loss is slower in urban areas and the net balance is more positive than in the surrounding rural areas and thus higher temperatures are present.
\end{abstract}

Keywords: Porous, Non Porous Pavement, Urban environment, thermal characteristics, Albedo, solar radiation

\subsection{Introduction}

It is a general knowledge that urban thermal environment has a higher air temperature than its surrounding area. Studies have shown that the primary reason for the modification of an urban environment is the reduction of the portion of natural surface and the increase of impermeable paved surfaces in urban areas. Thermal environment comprises of thermal pollution which is excess heat trapped in urban areas. This is caused by orientation of building, materials and texture of the building. Multiple reflections is responsible for thermal pollution, it is the excess heat which is not suitable for life.

The history of Urban Heat Island can be traced back 1880 in $18^{\text {th }}$ Century after the industrial Revolution in United Kingdom (Gartland, 1960), since then, it has being one of the major problems confronting Urban dwellers. Recently, in urban areas, buildings and paved surfaces have gradually replaced preexisting natural landscape. As a result, solar energy is absorbed into paved materials and rooftop, causing the surface temperature of urban areas to become $10-21{ }^{0} \mathrm{C}$ higher than the ambient air temperatures. As population grows, they tend to modify a greater and greater area of land and have a corresponding increase in average temperature. Temperature is one of the important element of urban centres; it is known that urban temperatures differ from those of sub-urban and rural areas after the sunset, the rural areas begin to cool rapidly, unlike urban, this depends on Topography, geological location and anthropogenic factors. Temperature modified the urban environmental characteristics and also contributes to the enhancement of dwellers internal behaviour. (Irfan et al 2001) Figure 1 depicts distribution of temperature over different region. 


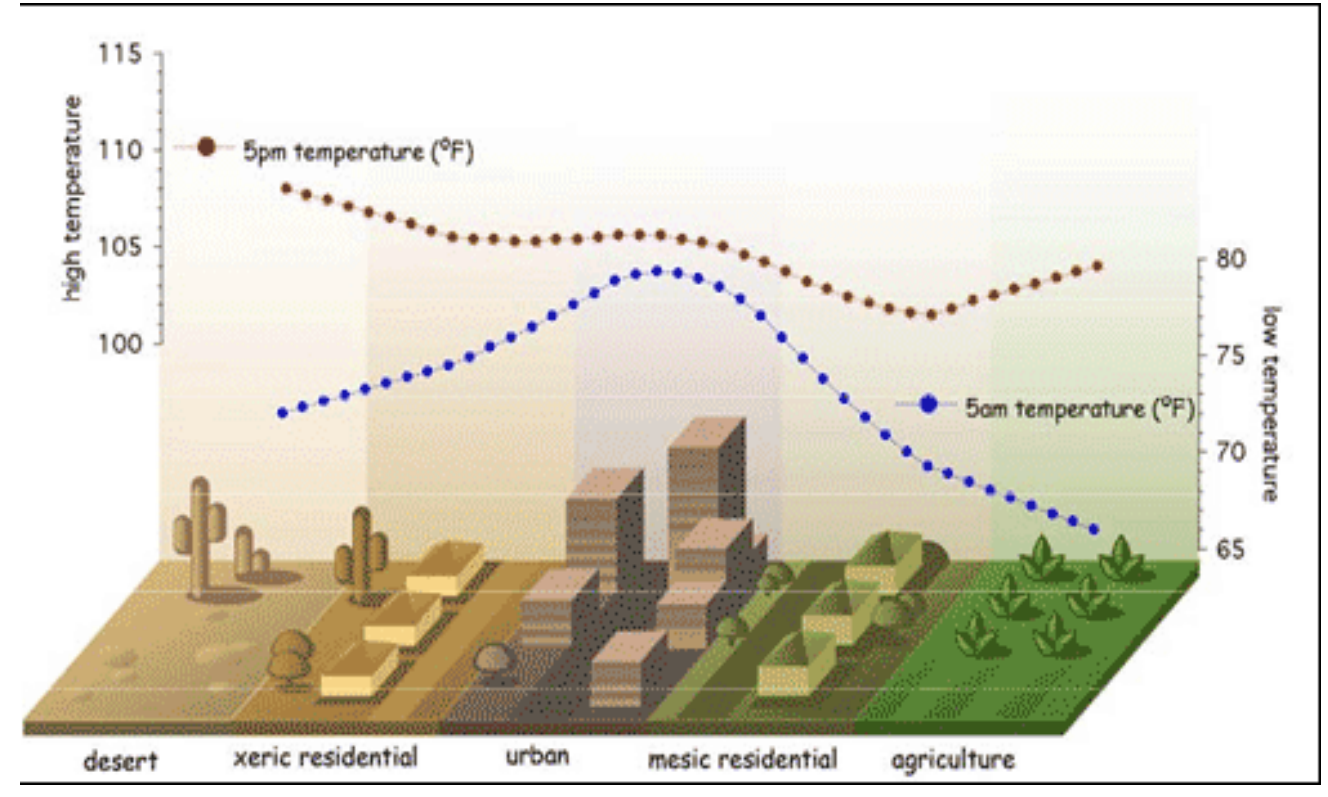

Figure 1: Ambient air temperature distributed over the various region

(Source: Golden, 2004)

An urban thermal environment is a metropolitan area which is significantly warmer and hotter than its surrounding rural and undeveloped areas, solar energy is absorbed by rooftops, pavements, structures, and facades which is then converted and released as heat energy into the air. Since the spacing of man-made structures is much denser in urban areas, more heat is released causing the outside temperature in a city to be increased thus hotter than rural areas.

The modified climate impact is prone to high heat in areas such as the city centre. These areas are usually densely populated with massive development to cater for all kinds of daily activities. These are also areas which become central points for people using the outdoor and indoor spaces; where they congregate, meet, crowd and carry out their daily activities. Thus, climate is one of the most influential factors that determine human comfort level in public areas and their social life as well. These confirm the position of many researchers including Sham and Jamaluddin (1987) who indicated that urbanisation has altered the city climate and it is made worst in most hot humid cities like Kuala Lumpur, Bangkok and Jakarta where climatic changes bring about the urban heat and atmospheric pollution with reduced humidity and the air is polluted with dust and pollutants and the surrounding temperatures increase.

In a related development, (Shahmohamadi et al 2009) mentioned that a tropical country like Malaysia, the temperature difference between urban and its surrounding sometimes can reach up to $10^{\circ} \mathrm{C}$. The replacement of the previous surfaces by built up surfaces significantly reduces the cooling effect of the green vegetation through its natural evapotranspiration processes Sham Sani (1987). Outdoor thermal environment is impacted by the built environment, e.g. anthropogenic heat, evaporation and evapotranspiration of plants, shading by trees and man-made objects, (Lin et al., 2010), and ground surface covering, such as natural grass and artificial pavement. Also, due to the albedo of pavements which affect the quantity of solar radiation reflected to the sky, 
the pavement with low albedo value is one of the main factor causes of the high air temperature and thermal discomfort for urban dwellers, (Tzu-Ping et al., 2011)

Therefore, an important process worthy of mention is that when there is an incoming or direct solar radiation from the sun, part of it is absorbed while some are reflected. This reflected solar radiation is responsible for modification of urban thermal environment which causes the reduction in the cooling effect of the surroundings.

\subsection{Methodology}

\subsection{Observational Methods}

A series of climatological experiments were conducted throughout the year from April 2010 to May 2011 to obtain meteorological data such as air temperature, relative humidity and wind velocity, surface temperature, solar radiation, upward \&downward longwave radiation were monitored above the sample surface located at International Islamic University (IIUM) Gombak campus $3^{0} 8 \mathrm{~N}, 101^{0} 42 \mathrm{~N}$ in Malaysia, (IIUM). The observations were primarily aimed at investigate the heating process inside various pavements. Figure 3 shows the description of experimental points.

The selected pavement surfaces were the representative of typical urban and sub-urban thermal environment. Although, measurements were carried out throughout one year, due to the limit of this paper, only a day observational results are presented. The information gathered over the observational periods was screened so as to exclude rainy, overcast and high mean wind speed days and eventually one set of data corresponding to $4^{\text {th }}$ April 2011 was chosen as representative fair weather conditions of tropic, where weather somewhat more inland was sunny and warm. The following Figure 2 depicts the observational site, which is located in the circulation of IIUM-Gombak Campus.

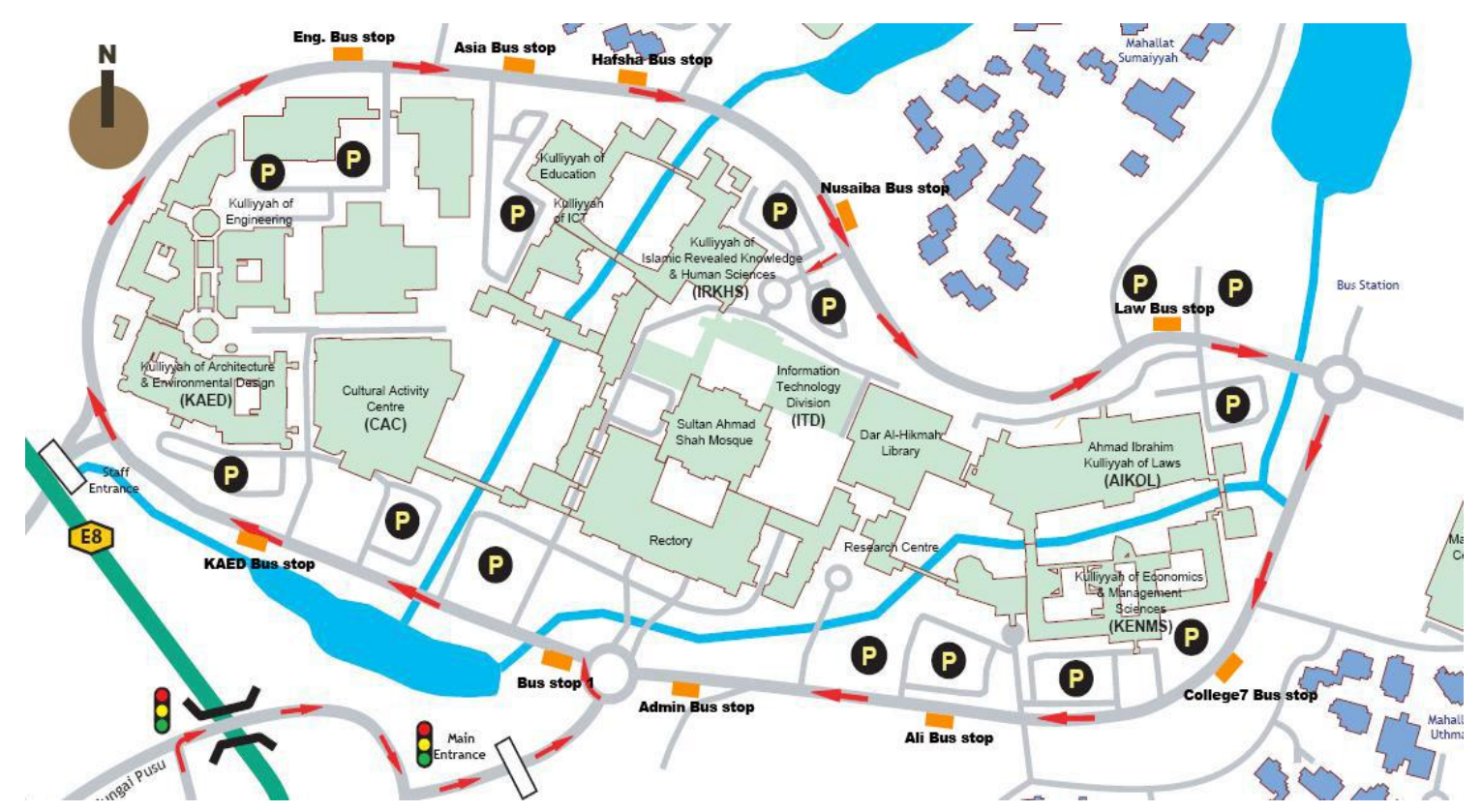

Figure 2: Observational Site, IIUM Gombak 
The general meteorological conditions of the observation site were measured. The ambient temperature (denoted as Ta for the purpose of this research) and relative humidity were measured using TESTO 625 with an accuracy of $+0.02^{\circ} \mathrm{C}$. During the observation, the wind speed was measured using anemometer with the accuracy of $0.01 \mathrm{~m} / \mathrm{s}$, upward \& downward longwave radiation were measured at interval of 15 minutes. List of equipment used were shown in Table 1.

Table1: List of equipment

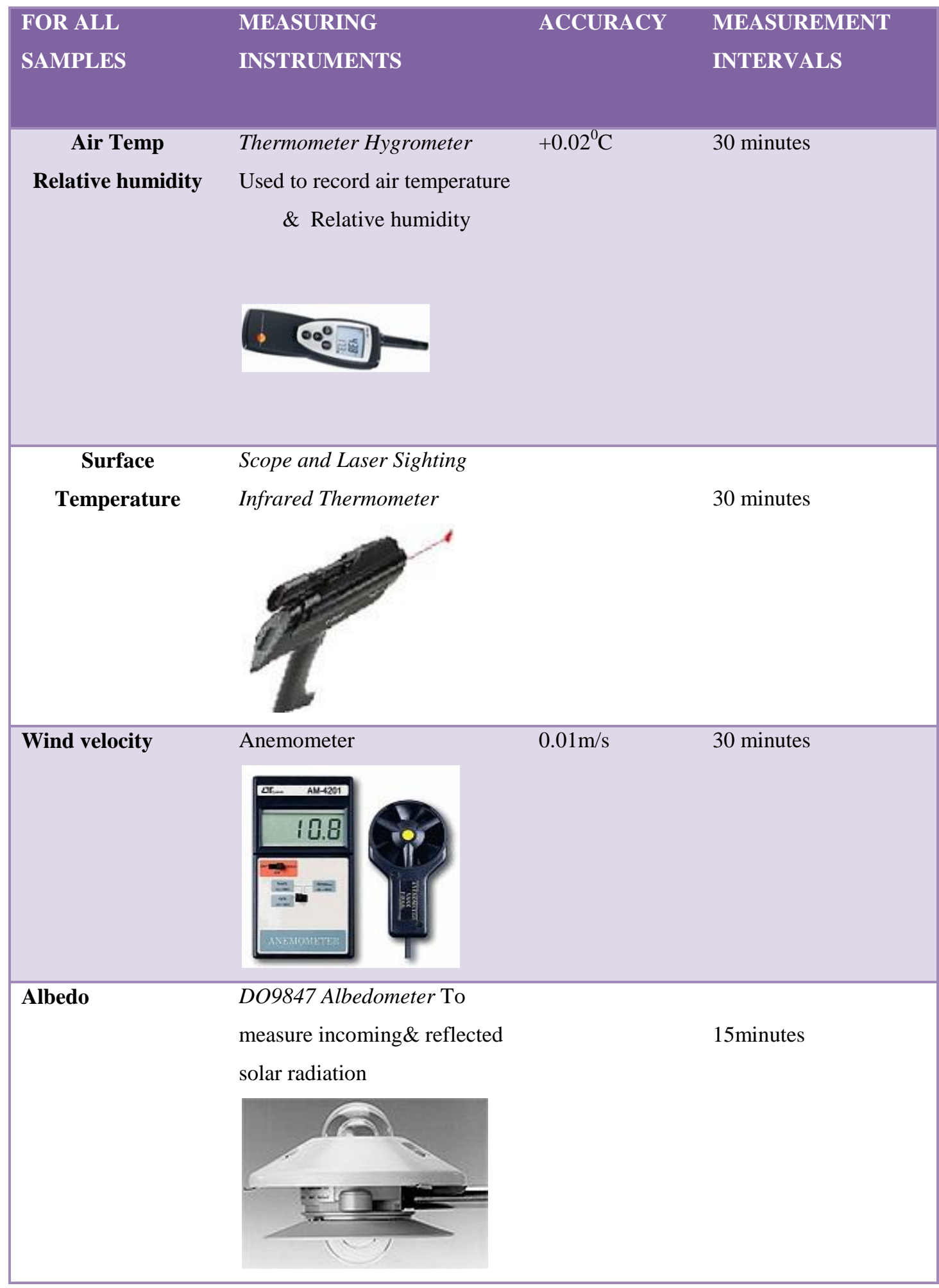


List of pavements that were observed through the experiment is shown in Table 2.

Table 2: List of pavements that were observed through the experiment

\begin{tabular}{|ll|}
\hline PAVEMENTS & Examples \\
\hline Porous & Coloured Interlocking bricks \\
\hline Non porous & Asphalt and concrete \\
\hline Natural pavement & Grass \\
\hline
\end{tabular}

\subsection{Data Analysis, result and discussion}

In this research, ambient air temperature, relative humidity, wind speed and surface temperature were measured. Generally, these are the essential parameters that enhance the modification of urban environment. Hence, they are micro-climate parameters.

From the air temperature (Table 3), humidity (Table 4) and wind speed values (Table 5) obtained from the five experimental points, the following were found which is presented in the form of charts

Table 3: Air temperature measurements of all the 6 bus-stops

\begin{tabular}{lllllll|}
$\begin{array}{l}\text { Local } \\
\text { hr. }\end{array}$ & \multicolumn{7}{c|}{ AMIBIENT AIR TEMPERATURE ${ }^{0}$ C } \\
& KAED & ENG & CLINIC & NUSAYBAH & LAW & USMAN \\
\hline $\mathbf{1 0 : 0 0 a m}$ & 29 & 31 & 32 & 30 & 31 & 31 \\
\hline $\mathbf{1 2 : 0 0 p m}$ & 35 & 34 & 34 & 33 & 33 & 33 \\
\hline $\mathbf{2 : 0 0 p m}$ & 37 & 36 & 38 & 35 & 35 & 36 \\
\hline $\mathbf{4 : 0 0 p m}$ & 39 & 37 & 39 & 37 & 36 & 37 \\
\hline $\mathbf{6 : 0 0 p m}$ & 35 & 33 & 37 & 34 & 29 & 28 \\
\hline $\mathbf{8 : 0 0 p m}$ & 28 & 27 & 31 & 28 & & 33 \\
\hline
\end{tabular}

The measured meteorological conditions of all the six bus stops are presented in Figure 4. The temperatures were low, increased upward and later decreased downward as the sun sets.

During the field experiment, it was observed that the solar radiation was the main factor altering the thermal performance of the surfaces. Results show that the surface temperature of pavements was significantly higher at noon. At around 4pm local time, the maximum ambient air temperature reached approximately $39^{\circ} \mathrm{C}$, while the percentage of relative humidity and the wind speeds were found minimum. These conditions are believed to be representative of tropical days in the study area. There were no significant differences in temperature during the morning hours and evenings which shows that the higher the solar intensity the higher the surface temperature. 


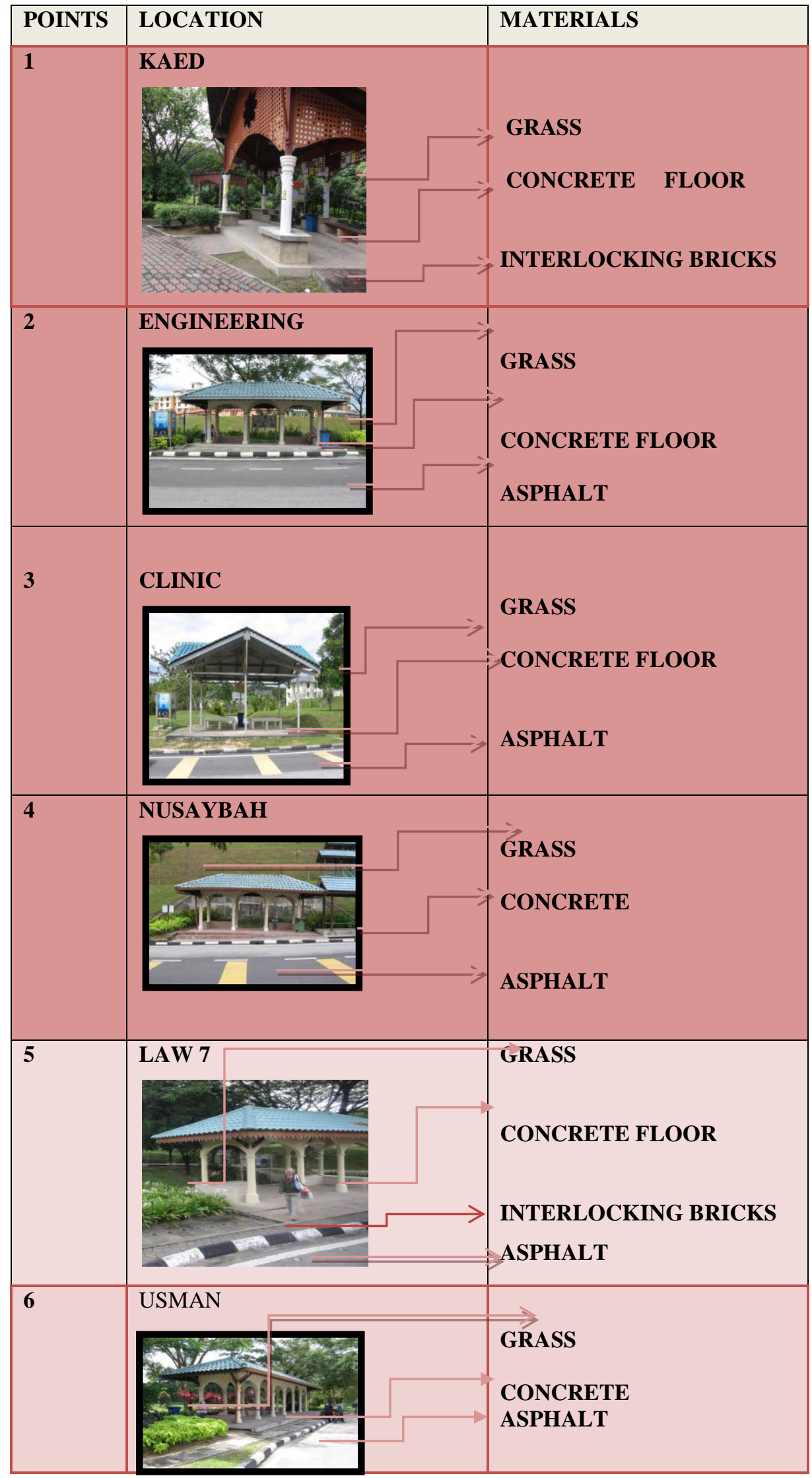

Figure 3: description of the experimental points 
Table 4: Relative humidity measurements of all the 6 bus-stops

\begin{tabular}{|c|c|c|c|c|c|c|}
\hline \multirow{2}{*}{$\begin{array}{l}\text { Local } \\
\text { hr. }\end{array}$} & \multicolumn{6}{|c|}{ RELATIVE HUMIDITY \% } \\
\hline & KAED & ENG & CLINIC & NUSAYBA & LAW & USMAN \\
\hline 10:00am & 51 & 52.5 & 55 & 53 & 46 & 54 \\
\hline 12:00pm & 46 & 44 & 40 & 44 & 43.5 & 46.5 \\
\hline 2:00pm & 35.5 & 37 & 29.5 & 36.33 & 35.5 & 37.5 \\
\hline 4:00pm & 34.5 & 35.5 & 37 & 34 & 32 & 33.5 \\
\hline 6:00pm & 65 & 63 & 60 & 61.5 & 61 & 62 \\
\hline 8:00pm & 62 & 69.5 & 62 & 63.5 & 62.5 & 62 \\
\hline
\end{tabular}

Table 5: Wind velocity measurements of all the 6 bus-stops

\begin{tabular}{|lllllll|}
$\begin{array}{l}\text { Local time } \\
\text { hr. }\end{array}$ & \multicolumn{7}{c}{ WIND VELOCITY M/S } \\
\hline & KAED & ENG & CLINIC & NUSAYBAH & LAW & USMAN \\
\hline $\mathbf{1 0 : 0 0 a m}$ & 0.19 & 0.9 & 0.5 & 1.3 & 1.5 & 0.3 \\
\hline $\mathbf{1 2 : 0 0 p m}$ & 1.77 & 0.5 & 1.16 & 0.48 & 1 & 0.7 \\
\hline $\mathbf{2 : 0 0 p m}$ & 2 & 1.2 & 0.24 & 3.2 & 1.3 & 0.7 \\
\hline $\mathbf{4 : 0 0 p m}$ & 1.2 & 1.1 & 1 & 1.67 & 1.2 & 0.7 \\
\hline $\mathbf{6 : 0 0 p m}$ & 0.85 & 0.9 & 0.6 & 2.6 & 0.6 & 0.5 \\
\hline $\mathbf{7 : 3 0 p m}$ & 1 & 0.43 & 0.9 & 1.7 & 0 & 0 \\
\hline $\mathbf{8 : 0 0 p m}$ & 0 & 0 & 0 & 0 & & 2.3 \\
\hline
\end{tabular}

It is important to reiterate that the energy budget of the near surface atmosphere depends on the pavement surface temperature which turns into the thermal processes below the surface. Meanwhile, the surface temperature of asphalt is higher than that of the other pervious paved surfaces or natural grass, which is due to the effect of water content and the net heat flux at the surface of nonporous pavement used for heating the surface layer of pavement. The temperature of natural grass surface is less than that of other surfaces due to evapotranspiration from grass surface. The diurnal surface temperature of asphalt and porous block decreases to less than $34^{\circ} \mathrm{c}$ and grass surface temperature decreases to less than air temperature. From the experimental results, it was found that surface temperature of the normal porous pavement was high. This can be explained by the effects of the pore size in pavement materials on the subsurface moisture transfer. The normal porous block, having large pores, cannot keep the water inside and dried up rapidly. This makes its surface temperature at noon as high as that of the normal impermeable concrete pavement. 

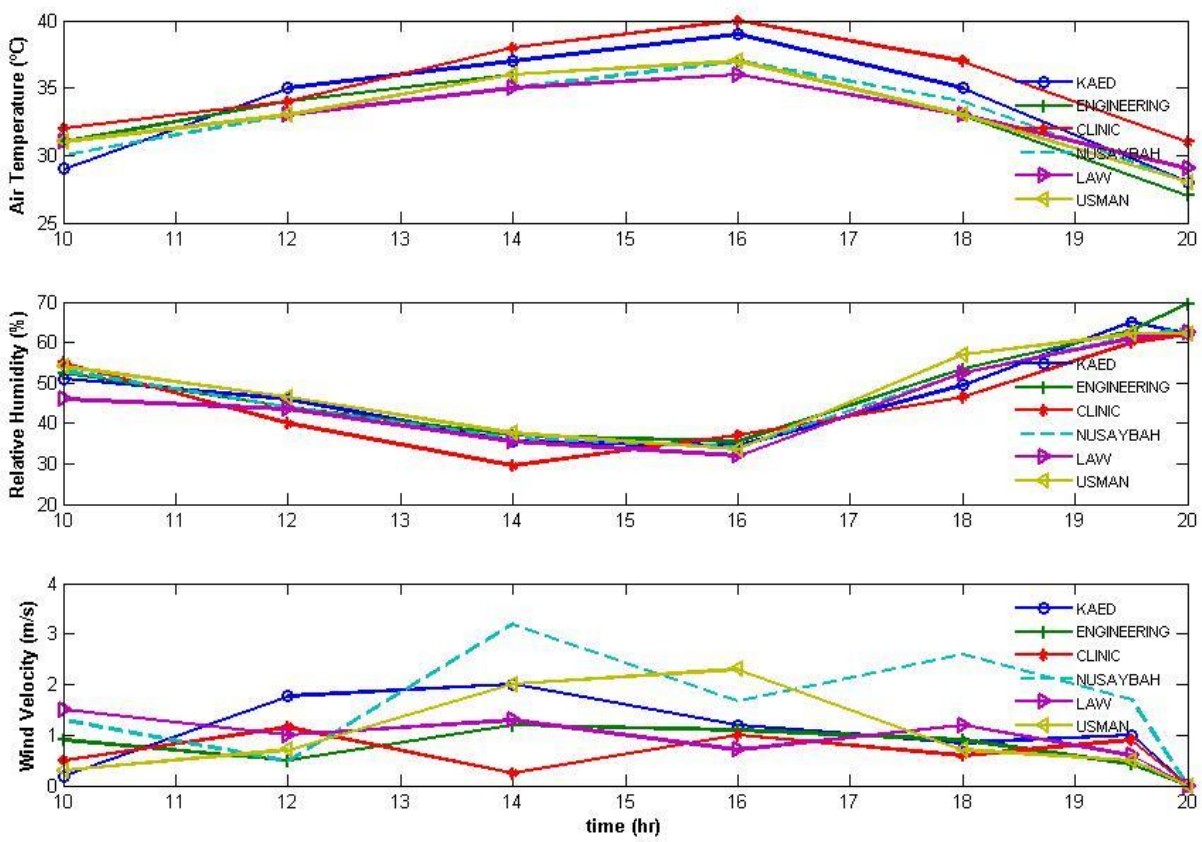

Figure 4: Meteorological conditions; Ambient Air Temperature, Relative humidity and Wind Velocity in six Experimental points.

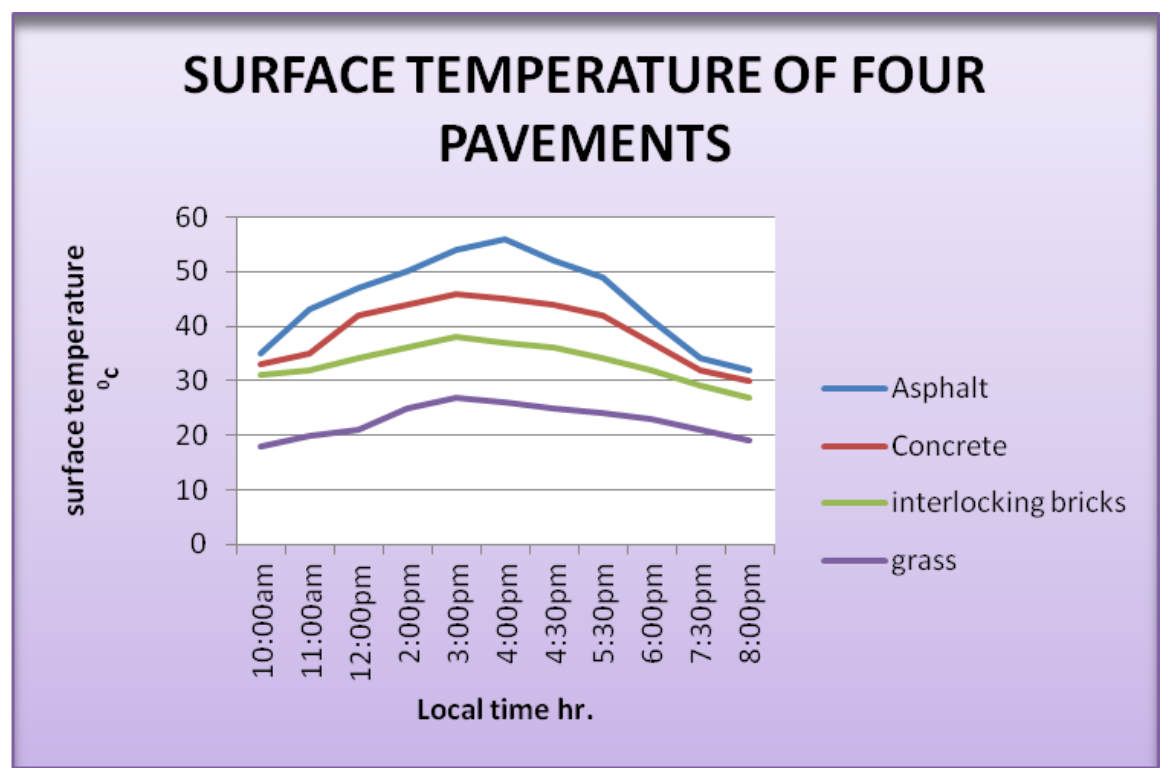

Figure 4:Temperature distribution $2 m$ above the surface

In the afternoon, the surface temperature of grass decreases very quickly hence, at the night, grass surface cools the atmosphere. This is because grass does not store incoming solar radiation received but reflects more of it unlike asphalt and concrete. Whereas, throughout the day, surface temperature of asphalt was always higher than that of the air temperature, thus the atmosphere is always heated. This is because asphalt does not allow evaporation process to take place causing thermal discomfort 


\subsection{Measurements of pavement albedos}

The albedos of pavements were also measured. This is because albedo contributes to the creation of heat island and it is one of the main parameters used to estimate Urban Heat Island. To measure the solar radiation we used a D09847 Pyranometer (Figure 5). This is faced downward to measure the reflected solar radiation from a surface and upward to measure the incident radiation which corresponds to the ratio of the albedo of the surface. Albedo values range from 0 , for perfect absorbers, to 1 , for perfect reflectors. In pavement structures, the topmost surface is the only layer which affects albedo. It is suitable to consistently investigate the energy budget within urban canopy (Taha et all 1992).

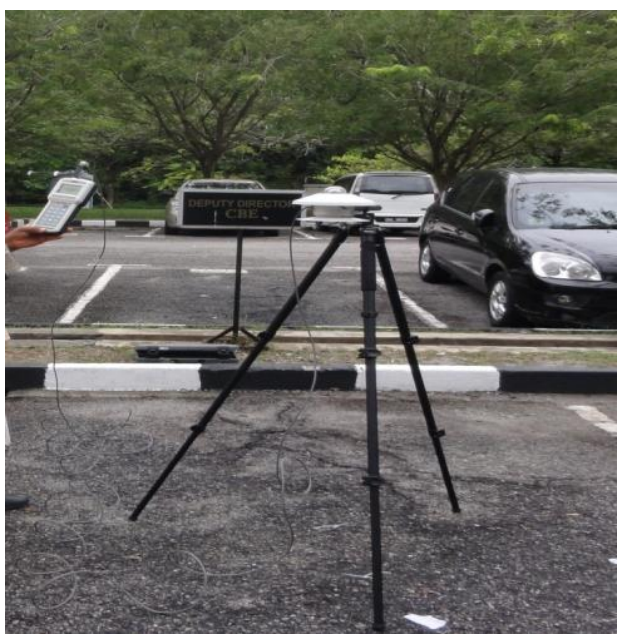

Figure 5: one of the instrumentation for the field experiment

Paved surfaces (such as highways, roads, runways, parking areas, sidewalks, and driveways) typically constitute about 30 to $40 \%$ of developed urban areas. Generally, light coloured surfaces have higher albedos, absorb less radiation and thus, have lower surface temperatures when exposed to the sun, relative to dark coloured surfaces (Akbari et al. 1989). Using high albedo materials reduces the amount of solar radiation absorbed through building envelopes and urban (Taha et al 1992) structures and keeps their surfaces cooler. The value of urban albedo is lower due to the solar radiation trapping effect, urban geometry; the value increases with decreasing solar elevation and the effect of multiple reflections.

From the literature, there exist the albedos of pavements found in cities and the temperature to which they are heated by sunlight. (Taha et al. 1992) reported the values of AC pavement albedos from 0.05 to 0.15 . The temperature of the air near the ground, which is what directly affects humans, is dependent on the absorption of sunlight by solid surfaces (Pometantz 2000).

This study conducted field experiment on three types of pavements (porous, non-porous and natural pavement) in one bus stop as a representative of others to obtain the albedo value through the measurement. The albedo value was derived by ratio of incoming solar radiation to outgoing. Also, the mean values of the pavement albedo were calculated and the following results were obtained as shown in Table 5 below. 
Table 5: Mean albedo of the four pavements

\begin{tabular}{|ll|}
\hline Mean albedo & Pavements \\
\hline 0.14 & Asphalt \\
\hline 0.18 & Concrete \\
\hline 0.29 & Interlocking bricks \\
\hline 0.35 & Grass \\
\hline
\end{tabular}

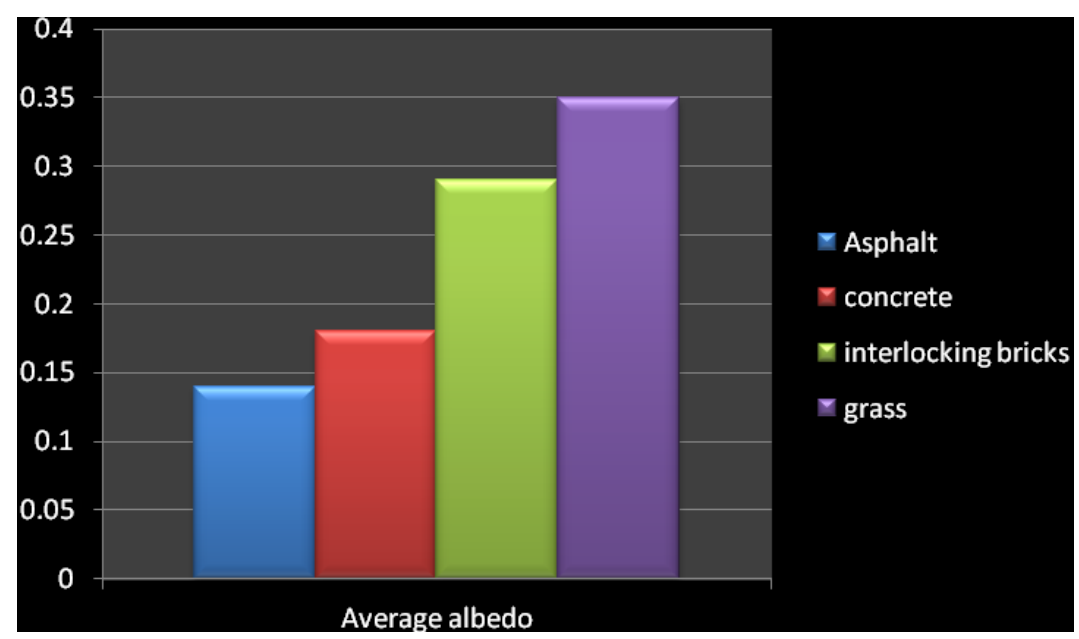

Figure 6: Depicts the average albedo value obtained from the field experiment.

Figure 6 above shows the mean albedo value of 3 field experiments for each pavement. Among the four pavements, asphalt has the least average value of 0.14 while the highest value of 0.35 was obtained from the grass. The lower value of asphalt albedo is one of the major factors responsible for thermal environment because it stored more solar radiation received and reflect less, whereas, materials with higher albedo such as grass help to balance the thermal environment since it reflects more radiation_(Tzu-Ping et al, 2010). The higher the albedo value the better it is for the environment.

From the experimental data, it was observed that there is an indirect relationship between surface temperature and surface albedo. Higher temperatures were observed on the surface with lower albedo and vice versa, e.g in grass, where the impact of evapotranspiration, shade and thermal capacity of soil is higher than in other pavements

\subsection{Discussion}

Urban thermal environment is modified due to effect of meteorological conditions such as air temperature, relative humidity and wind speed as well surface temperature and albedo. 
This paper is an attempt to bring to the fore the useful interconnectivity between micro climate parameters and albedo to determine the heating effect of urban pavements.

In general, urban thermal environment is impacted by the built environment, e.g. anthropogenic heat, evaporation and evapotranspiration of plants, shading by trees and man-made objects (Lin et al. 2010), and ground surface coverings, such as natural grass and artificial pavement. Due to the albedo of pavements affect the quantity of solar radiation reflected to the sky, the pavement with low albedo value is one of the main factor cause the high air temperature and thermal uncomfortable for human beings. (Pometantz et al, 2000) Surface temperature depends on absorption degree, if the absorption is high, surface is hot.

Studies (Asaeda et al_1993, Didel and Dilshan 2009) revealed that around noon, surface temperature of Asphalt pavement can reach more than $55^{\circ} \mathrm{C}$, and the surfaces releases more than $350 \mathrm{~W} / \mathrm{m}^{2}$ and $600 \mathrm{~W} / \mathrm{m}^{2}$ to the atmosphere in the form of sensible heat and longwave radiation, respectively. The sensible heat directly heats the air, while the upward longwave radiation can increase the thermal load on the pedestrian and cause great thermal discomfort. Similarly, less intense, the heated concrete pavement can also cause great thermal discomfort to pedestrian (Jonatha and Carelli 2010).

The main reason for the increase in temperature at the surface of the normal impermeable pavement is the lack of evaporation, which at its peak around noon can be as large as $400 \mathrm{~W} / \mathrm{m}^{2}$ and consumes a large portion of net radiation to the surface. Due to intensive evaporation, the surface temperature of bare soil at noon is only around $40^{\circ} \mathrm{C}$ and decreases to lower than that of the air soon after sunset (Asaeda et al 1993, Didel and Dilshan 2009).

In spite of the lower value of albedo over grass, the grass temperature was always lower than the other surfaces found in the study area. Thus, it is desirable that a kind of pavement which enables the exchange of water between the pavement and the underlying soil, and consequently enables the evaporation at the ground surface be used in the urban areas. (Asaeda et al, 1993; Didel and Dilshan ,2009) found that among various porous pavement materials, ceramic porous pavement can be used for this purpose.

It was also found that air temperature in the observed area was high, this could be due to reasons such as: the fact that the place is located inside the educational institution and large value of anthropogenic heat released from traffic (buses, cars, motorcycles etc), air conditioning, construction of new building opposite Architecture faculty and other human activities going on campus which might heat the air.

\subsection{Conclusion}

Based on the observed climatological data, the utilization of the normal porous pavement does not improve the thermal environment because the surface for this type of pavement is usually dry and evaporation cannot occur. The non-porous surface materials can absorb a large amount of incoming net radiation, which increases its surface temperature and causes the variation of urban thermal environment. From the observation of the experimental area, it is evident that porous pavement is more reliable than non-porous pavement for balancing 
the urban thermal environment from the point of evaporation. The results of field experiment also indicate that high albedo pavement i.e grass will help to mitigate the hot condition of the study area.

The result obtained from experiment showed the extent to which the uses of different building materials enhance Urban Thermal Environment. This paper has highlighted the possibility and importance of combining micro climate parameters and albedo in the determination of urban thermal environment.

\subsection{References}

Akbari, H., Rosenfeld H., and Taha H.. 1989. Cooling urban heat Islands' American foresty Association- Make Our Cities Safer For Trees Fourth Urban Forestry Conference, St Louis, MO 15-19 October 1989

Asaeda T., Vu, T., Wake, A., 1993. Heat storage of pavements and its effect on the lower temperature, Atmospheric Environment.

Taha H., Sailor D. and Akbari H., 1992. High albedo materials for reducing cooling energy use, Lawrence Berkeley Lab. Rep. 31721 IJC-350, Berkeley, CA, 1992.

Didel M. J and Dilshan R. 2009. The effect of water on outdoor paved surfaces A strategy to mitigate urban heat island, University Teknology Malaysia

Gartland, L., 2008, Heat Islands: Understanding and Mitigating Heat in Urban Areas. Earthscan Ltd

Golden, J. (2004). The Built Environment Induced Urban Heat Island Effect in Rapidly Urbanizing Arid Regions- A Sustainable Urban Engineering Complexity. Journal of integrative Environmental Sciences

Irfan N, Adnan Z, Nadeemullah K, (2001), Minimising The Urban Heat Island Effect Through Lanscaping, NED Journal of Architecture and Planning, Vol One.

Jonatha J. Carelli 2010, Design and Analysis of an Embedded pipe Network in Asphalt Pavements to Reduce the Urban Heat Island Effect, Worcester Polytechnic Institute

Lin, T., Matzarakis, A., \& Hwang, R. (2010). Shading effect on long-term outdoor thermal comfort. Build. Environ. 45, 213-221.

Pometantz M., Pon B., Akbari H. \& S.Chang, (2000). The effect of pavements' temperatures on air temperature in large cities (LBNL-43442), Lawrence Berkeley Laboratory, Energy Analysis Program, Berkeley, CA.

Shahmohamadi P, A. C.-A.-N. (2009). The Effect of City Parameters on Urban Heat Island. Proceedings of theregional Engineering /postgraduate Conference. Bangi, Selangor: Department of Architecture, Faculty of Engineering and Built Environment, Universiti Kebangsaan Malaysia,.

Sham Sani, (1987). Urbanization and the Atmospheric environment in the low tropics: Experiences from theKlang Valley Region, Malaysia. Bangi: Penerbit University Kebangsaan Malaysia.

Sham Sani \& Jamaluddin, Jahi. (1987). Post-merdeka development and air quality degradation in Malaysia. In AMIC-CDG-COMCON-UKM Workshop on Mass Media and the Protection of the Environment: Kuala Lumpur, Sep 28-Oct 10, 1987. Singapore: Asian Mass Communication Research and Information Centre.

Tzu-Ping L., Andreas M., Ruey L. H and Ying-Che H,( 2010). Effect of pavements albedo on long-term outdoor thermal comfort, National Formosa University, Taiwan 